\title{
¿REVOLUCIÓN MILITAR O DEVOLUCIÓN MILITAR? CAMBIO Y CONTINUIDAD EN LA EDAD MODERNA MILITAR
}

\section{Military Revolution or Military Devolution? Early Modern Military Change and Continuity}

\author{
David PARROT \\ Universidad de Oxford \\ Correo-e: david.parrott@new.ox.ac.uk
}

RESUMEN: Este artículo pretender revisar el paradigma histórico del desarrollo militar durante la Edad Moderna como un proceso dirigido por el Estado, relacionado con los conceptos de centralización y control burocrático. Aunque los historiadores han abordado la intensa utilización de mercenarios y apoyo y abastecimiento de ejércitos y armadas por contratistas privados, no ha sido considerado convenientemente el posible significado de que, en realidad, fue un mecanismo viable y predominante en el despliegue de las fuerzas armadas del Estado. Mediante el análisis del desarrollo de todas las circunstancias que surgen a raíz de la práctica de hacer la guerra a través de contratistas privados a partir del siglo XVI en adelante, se concluye que esta forma de guerra no fue una anomalía, a la que recurrieron unos gobernantes débiles o irresponsables, sino un medio lógico para movilizar recursos dentro del contexto de las limitaciones de los gobiernos de la Edad Moderna y de su dependencia de los recursos y cooperación de la elite.

Palabras clave: Estado, Edad Moderna, Historiografía, Guerra, Revolución Militar, Estado fiscal-militar, Suministros militares, Empresarios militares. 
ABSTRACT: This article seeks to take issue with the historical paradigm of military development in the early modern period as a state-directed process linked to ideas of centralization and bureaucratic control. Although the widespread deployment of mercenaries and the support and supply of armies and navies via private contracting has been noted by historians, their significance as viable and predominant mechanisms for deploying military force have not been properly examined. By exploring the development of all aspects of warfare waged through private contracting from the later sixteenth century onwards, it will be argued both that this style of warfare was not some anomaly, undertaken by weak or irresponsible rulers, but a logical means to deploy resources in the context of the limitations of early modern governments and of their dependence on the resources and cooperation of elites.

Key words: State, Early Modern, Historiography, War, Military Revolution, Fiscal-Military State, Military supplies, Military Entrepreneurs.

Durante varias décadas hemos sido testigos de un aumento continuo de la privatización de las actividades militares. El uso de contratistas y compañías privadas para apoyar, aumentar y suplir las tropas reclutadas y controladas directamente por el Estado ha sido la característica determinante de las fuerzas militares occidentales desde la década de 1980. No obstante, en la misma medida en que las percepciones populares de los sistemas militares actuales no han llegado a comprender la escala y el alcance del significado político de esta contratación de servicios militares externos, la mayor parte de los historiadores tampoco han captado el significado real de lo que puede llamarse la otra gran «devolución militar» de los siglos XVI y XVIII ${ }^{1}$.

Ha sido solo en los últimos cuatro o cinco años cuando numerosos libros, artículos y conferencias han profundizado en el abastecimiento militar y el papel de las empresas privadas militares durante la Edad Moderna ${ }^{2}$. Esto ha llevado a

1. La única excepción destacable de este olvido generalizado es, por supuesto, el trabajo de I. A. A. Thompson, cuya monografía y tesis, War and Government in Habsburg Spain, 1560-1620, Londres, 1976, continuada en una serie de artículos y capítulos en obras colectivas, definieron los términos del debate sobre la administración estatal y privada -administración y asiento- en la España de los Habsburgo. Debe elogiarse el esfuerzo de la revista Studia Historica por avanzar en el trabajo de Thompson con nuevas investigaciones españolas y con una dimensión más europea.

2. Bowen, H. y González Enciso, A. (eds.): Mobilizing Resources for War. Britain and Spain at Work during the Early Modern Period. Pamplona, 2006; Bannerman, G.: Merchants and the Military in $18^{\text {th }}$ Century Britain. British Army Contracts and Domestic Supply, 1739-1763. Londres, 2008; Torres Sánchez, R. (ed.): War, State and Development. Fiscal-Military States in the Eighteenth 
cuestionar una serie de supuestos sobre la guerra en la Edad Moderna y su relación con los cambios políticos y sociales. Mi libro, The Business of War. Military Enterprise and Military Revolution in Early Modern Europe, es un intento de contribuir a este clima de revisión ${ }^{3}$. En él hacemos una valoración de las ventajas y utilidades operacionales y logísticas conseguidas por aquellos estados y sociedades con el empleo de contratistas militares durante la Guerra de los Treinta Años, relacionándolo con un estudio más amplio del desarrollo del espíritu empresarial en el terreno militar durante la Edad Moderna. Todo con el objetivo de revisar los prejuicios históricos e historiográficos que han marginalizado el estudio de la privatización militar y su relación con la construcción del Estado.

El concepto que típicamente ha definido la guerra y la sociedad en la Edad Moderna no es, ciertamente, la «revolución militar», sino la «devolución militar». Desde su aparición a mediados de la década de 1950, la conocida tesis de Michael Roberts, esto es, que ciertos cambios en la táctica y la organización militares podrían ser vinculados con procesos más amplios de transformación política y social, ha sido el principal eje del posterior debate sobre la guerra y la sociedad de la Edad Moderna ${ }^{4}$. Su concepto de «revolución militar» es el que, de hecho, se ha situado en la cima del conjunto más extendido de interpretaciones, teorías y hasta creencias, que juntas han proyectado una larga sombra sobre la manera en la que se ha entendido e interpretado el papel del recurso a la privatización militar en la tradición historiográfica europea. Aunque los estudios realizados sobre organización militar y la guerra sirvieron para mostrar la existencia y el empleo por el Estado de mercenarios, empresarios militares y logística privada, la valoración de su significado ha sido más discutible. En la mayoría de estos estudios sobre la guerra, la privatización militar es aún una cuestión periférica o, lo que aún es más grave, un callejón sin salida, esto es, una realidad histórica que termina desapareciendo por el ascenso del Estado. El trabajo clásico sobre el espíritu empresarial militar de Fritz Redlich, German Military Enterpriser and bis Work Force, nos proporciona un ejemplo valioso del problema historiográfico y de lo que podríamos llamar «el pensamiento clásico». Redlich nos ofreció un detallado estudio de los empresarios militares, de la vida de los implicados en

Century. Pamplona, 2008; Knight, R. y Wilcox, M.: Sustaining the Fleet, 1793-1815. War, the British Navy and the Contractor State. Woodbridge, 2010; Förster, S., Jansen, C. y KronenitTter G. (eds.): Rückkehr der Condottieri? Krieg und Militär zwischen staatlichem Monopol und Privatisierung: Von der Antike bis zur Gegenwart. Paderborn, 2010; Conway, S. y Torres Sánchez, R. (eds.): The Spending of States. Military Expenditure during the Long Eighteenth Century: patterns, organization and consequences, 1650-1815. Saarbrücken, 2011; Harding, R. y Solbes Ferre, S. (eds.): The Contractor State and Its Implications, 1659-1815. Las Palmas, 2012.

3. Editado por Cambridge University Press en el 2012.

4. Roberts, M.: «The Military Revolution, 1560-1660». Belfast, 1956; Segunda edición en Roberts, M.: Essays in Swedish History. Londres, 1967, pp. 195-225. 
«el trato de soldados», pero también de los costes, los mecanismos y los peligros inherentes a la contratación de tropas ${ }^{5}$. De los datos proporcionados por Redlich surge con fuerza la imagen negativa de un empresario militar, que es presentado como un militar, que ejerce constantemente pero frustrado, que termina siendo pernicioso para todos con los que se relaciona: autoridades, súbditos, soldados y hasta para sí mismo. Los aparentemente pocos casos de éxito profesional y supervivencia que se encuentran hasta el siglo XviII son, en el pensamiento de Redlich, una excepción en una evolución que todo indica que estos empresarios militares iban hacia su extinción. Si sobreviven en algunos estados alemanes es solo por su menor importancia, con un carácter residual y que, e incluso entonces fue solo una consecuencia de la insignificancia y debilidad de los principados alemanes.

Esta interpretación negativa y reduccionista de la presencia de los empresarios militares se ha repetido constantemente en la historiografía, pese a que buena parte de sus supuestos podrían ser fácilmente cuestionados, y toda la visión invertida. Así, el mantenimiento de una fuerza reclutada y administrada exclusivamente por el Estado podía ser, en realidad, una anomalía en una mirada más extendida de la historia europea. Del mismo modo, el esfuerzo de los estados por establecer ejércitos y armadas bajo control exclusivamente estatal, unido al mantenimiento de un monopolio estrecho del Estado sobre las fuerzas militares, aparece como un objetivo y una destacada preocupación de los estados europeos desde 1770 hasta aproximadamente 1960. En realidad, en el largo plazo, podemos afirmar que el patrón característico del arte europeo de la guerra, desde las polis de la Grecia clásica hasta el Ancien Régime del siglo xviII, y una vez más comenzando a partir del último medio siglo hasta hoy en día, ha sido precisamente la contraria, es decir, la organización de las fuerzas armadas a base de contratos con proveedores privados, ya sea para el reclutamiento y mantenimiento de marineros y soldados, o mediante la utilización de recursos privados con los que conseguir asegurar los suministros militares y hasta la logística militar. Sin embargo, la tradición castrense occidental y la historiografía han restado importancia o incluso negado esta realidad básica. Por el contrario, se ha establecido una idea fundamental, que aparece persistente en la historia, que insiste en el creciente control estatal de las fuerzas militares. Una idea acuñada bajo el rubro de la constante construcción de un «monopolio de la violencia» asociado a la construcción del Estado. La vitalidad de esta interpretación determinista del fortalecimiento militar en la construcción del Estado establecido por Redlich en su gran obra ha dejado poco espacio para valorar las realidades históricas que sugieren la existencia de iniciativas, organizaciones y finanzas privadas en el actividad militar.

5. The German Military Enterpriser and his Work Force, $14^{\text {th }}-18^{\text {th }}$ Centuries. Vierteljahrschrift für Sozial - und Wirtschaftsgeschichte. Beihefte 47, 48, 2 vols., Wiesbaden, 1964. 
Era relativamente fácil mantener semejante énfasis en el creciente control estatal de ejércitos y armadas, cuando el resultado final del proceso histórico parecía ser tan evidentemente: el establecimiento de unas fuerzas armadas nacionales bajo el completo mando del Estado. Hasta mediados del siglo xx era posible conjeturar un «fin de la historia militar», en el cual la cualidad determinante de las fuerzas armadas modernas era su integración estructural dentro de la administración del estado, un proceso que parecía ser tan completo como irreversible. No obstante, las transformaciones militares experimentadas durante las últimas décadas suscitan dudas sobre este proceso aparentemente inexorable, e indudablemente han ayudado, explícita o implícitamente, a impulsar el estudio del empresario militar. Sin embargo, nunca fue el caso que el énfasis histórico en fuerzas militares bajo control estatal se asentase pura y simplemente en una idea de inevitabilidad histórica. Otras presunciones mucho menos problemáticas han tomado parte en la formación de opiniones sobre el desarrollo de las fuerzas militares en Europa durante la Edad Moderna.

Si los historiadores de la Europa de la Edad Moderna han interpretado las transformaciones en los patrones del arte de la guerra desde el siglo xv hasta el XVIII como un constante e irreversible aumento y perfección del control estatal, en parte se explica por la extensa creencia que atribuye, casi como un axioma, la inferioridad de la organización militar privada. Aquí se aprecian dos suposiciones entrelazadas y negativas. La primera es una generalizada preocupación moral y legal sobre la utilización de soldados mercenarios, y de cualquier negocio de apoyo militar, cuyas actividades no parecen tener una justificación más allá del afán de lucro personal. Aun cuando aquellos que prestan sus servicios fueran compatriotas o súbditos del Estado o gobierno beligerante, siempre suscitan sospecha y recelo la existencia de unos soldados que prestaban sus servicios de forma voluntaria e individual y por sus propios motivos ${ }^{6}$. Del mismo modo, y es una segunda suposición, aquellos empresarios militares o contratistas privados involucrados en la gestión de recursos y operaciones militares se consideran igualmente culpables, especialmente al valorarse que sus beneficios personales se verían directamente acrecentados por la extensión y prolongación de la actividad bélica.

Si los reparos morales son una parte de estos supuestos, podemos considerar que se potencian con una convicción igualmente poderosa y pragmática: que la contratación externa de la guerra es, desde un punto de vista militar, auto-destructiva. Es decir, el ejercicio de fuerza militar se debería confiar únicamente a aquellos cuya lealtad se puede asegurar por una identidad nacional y obediencia compartidas.

6. Percy, S.: Mercenaries. The History of a Norm in International Relations. Oxford, 2007; Thomson, J.: Mercenaries, Pirates and Sovereigns. State Building and Extraterritorial Violence in Early Modern Europe. New Haven-Londres, 1994. 
$\mathrm{El}$ «ejército ciudadano» concebido por Maquiavelo, respaldado por numerosos humanistas y luego escritores nacionalistas, contrasta vivamente con el soldado mercenario, que se alista solo por dinero y que lucha sin afiliación territorial o ideológica ${ }^{7}$. Adoptar una estrategia decisiva, pero potencialmente costosa, sería completamente contraria a los intereses de soldados asalariados y sus capitanes, cuyos propios intereses preferirían un conflicto prolongado y poco arriesgado que les proporcionase empleo por el máximo tiempo posible.

Estos argumentos negativos en contra de las fuerzas militares privadas pueden ser convincentes, pero hay argumentos contrarios que sugieren que construcción de Estado y recurso a empresarios militares no son incompatibles. Es más, el Estado pudo haberse desarrollado también mediante el recurso a las actividades militares privadas. Conviene tener presente la extensa historiografía que hay sobre la formación del Estado y la construcción del Estado moderno, y las diversas maneras en que implican el conflicto armado y sus exigencias.

Un punto de partida de tales premisas se encuentra en los historiadores decimonónicos, que analizaron el ascenso de Brandeburgo-Prusia. Prusia podría ser presentada como el «tipo ideal» de un enlace directo entre la centralización administrativa y unas fuerzas armadas financiadas y controladas directamente por el estado. Hacia 1740, esta síntesis entre Estado y ejército había servido para formar un ejército permanente de 80.000 hombres, que se vio incrementado en las posteriores guerras encadenadas desde mediados del siglo xviII, y que sirvió, en definitiva, para el establecimiento de Prusia como una gran potencia por sus propios méritos. La presentación de la organización castrense prusiana, tanto como la causa del poder centralizador estatal como su escenario principal de operaciones, puede parecer algo específico, pero la idea fue utilizada y repetida en las historias nacionales de otros países europeos. Clave por su influencia en esferas más amplias de la creación de estados, esta relación entre Estado y Ejército también ha sido analizada por estudios que atraviesan las fronteras entre la historia y las ciencias sociales. Aún más decisivos que el análisis de los vínculos entre la guerra y la burocracia de Max Weber son los trabajos de Otto Hintze. Aunque también recurre frecuentemente al caso de Brandeburgo-Prusia, Hintze dirige el debate hacia cuestiones conceptuales más amplias en cuanto a los cambios políticos y constitucionales en Europa durante los siglos XVII y XVIII ${ }^{8}$. Para Hintze, las exigencias para crear y mantener un ejército

7. Mallett, M. cuestiona estas presuposiciones en Mercenaries and their Masters. Warfare in Renaissance Italy. Londres, 1974; $2^{\mathrm{a}}$ edición, 2009.

8. Hintze, O.: Historical Essays, ed. F. Gilbert, Oxford, 1975, véase pp. 33-63, «The Hohenzollern and the Nobility»; pp. 178-215, «Military Organization and the Organization of the State»; pp. 267-301, «The Commissary and His Significance in General Administrative History: A Comparative Study». Hintze, O.: Gesammelte Abhandlungen zur allgemeinen Verfassungsgeschichte, ed. por G. Oestreich. 3 vols.; Göttingen, 1962-1967, véanse especialmente: i. 321-358, «Der österreichische 
permanente fueron claves para determinar la formación y el carácter del Estado, y proporcionar una explicación detallada de las estructuras y funcionamiento estatales?. A su juicio, el ejército permanente fue el factor decisivo en la transformación de los estados europeos en monarquías centralizadas, sostenidas por un poder represivo efectivo, y dirigidas por funcionarios profesionales.

Las interpretaciones y revisiones sucesivas de las relaciones entre la guerra de la Edad Moderna, el Estado y el cambio político han desafiado el determinismo de este modelo y han puesto de relieve una variedad de consecuencias políticas. La sencilla ecuación de que, en el caso de que el Estado no fracase, la coacción militar generará un poderoso Machstaat centralizado se puede demostrar que es solo una de una multitud de posibles productos políticos. Ha habido un destacado interés en la investigación de la «excepcionalidad» de la Europa noroccidental, a través de los ejemplos de la Gran Bretaña y las Provincias Unidas de los Países Bajos, por examinar las diferencias halladas en los sistemas estatales de la Europa Oriental, y destacar las varias maneras en que los poderes preexistentes de las instituciones representativas $\mathrm{u}$ otras instituciones que compartían el poder podían canalizar sus relaciones y tensiones en determinadas soluciones políticas ${ }^{10}$. Aunque estos estudios señalan diferentes soluciones constitucionales e indican, el desarrollo de distintos sistemas de gobierno, en realidad, poco se ha avanzado en cuanto a cómo todo este proceso puede producir distintos resultados en lo que se refiere a modelos diferentes de organización militar. Parece suficiente con sostener, y seguir repitiendo, la idea de la existencia de una relación entre el avance progresivo del control estatal y la administración central de los ejércitos y armadas.

La idea de que la creación del Estado implica necesariamente perseguir el monopolio de una fuerza militar controlada directamente por agentes del Estado, no está menos asentada que una serie de presunciones implícitas sobre la competencia y el aumento del poder del Estado. En esto han sido especialmente influyentes los argumentos esgrimidos por Frederic Lane, quien sostiene que un monopolio de coerción siempre prevalecerá porque puede proporcionar protección de forma más económica: «la mera actividad de producir y controlar violencia estimula el monopolio, porque la competencia dentro del reino subiría los costes...

und der preußische Beamtenstaat im 17. und 18. Jahrhundert; Eine vergleichende Betrachtung» 1901; i. 424-456, «Machtpolitik und Regierungsverfassung», 1913; iii. 164-203, «Der Ursprung des preußischen Landratsamts in der Mark Brandenburg», 1915.

9. «Machtpolitik und Regierungsverfassung», i. 429.

10. Aparte del gran número de trabajos que examinan estados específicos, véanse estudios generales como: Tilly, C.: Coercion, Capital and European States AD 990-1990. Oxford, 1990; Downing, B.: The Military Revolution and Political Change. Origins of Democracy and Autocracy in Early Modern Europe. Princeton, 1992; Ertman, T.: Birth of the Leviathan. Building States and Regimes in Early Modern Europe. Cambridge, 1997. 
La producción de violencia disfrutaba de economías escala» ${ }^{11}$. A medida que los estados se veían involucrados en guerras mayores y más exigentes, la lógica de fuerzas militares controladas por el Estado parece, en la tesis de Lane, irresistible.

Esta interpretación puede ser al menos discutible. La «presión de la guerra» en la mayoría de los debates tradicionales sobre la evolución del Estado es presentada simplemente en términos de un aumento en la escala y costes de las operaciones y fuerzas militares. No obstante, la respuesta del Estado a esta presión podría ser, por ejemplo, el reclutamiento de ejércitos (o armadas) a una escala sin precedentes de tropas contratadas en un bien organizado mercado internacional de mercenarios. Este fue el caso de los estados en Europa Occidental durante la primera mitad del siglo xvi, cuando, por ejemplo, la corona francesa levantó grandes ejércitos, de los cuales hasta un $70 \%$ era de mercenarios suizos y alemanes ${ }^{12}$. Tales fuerzas militares necesitaron también que el Estado produjera recursos financieros inmensos, para evitar la consecuente oposición doméstica y para expandir las competencias y funciones de ciertos aspectos de la administración, pero la conexión directa con el control creciente del Estado sobre los militares necesariamente no existió. ¿Por qué entonces encontramos la premisa implícita en casi todas las teorías y análisis de la creación de estados de que el objeto político del Estado fue no solo el reclutamiento y mantenimiento de fuerzas armadas sin precedentes, sino conseguir ese objeto con una mayor estructura de control estatal directo de dichas fuerzas armadas?

La respuesta nos trae otra vez al argumento de Michael Roberts, y al debate consiguiente sobre la realidad, periodización y significado de una «revolución militar» en la Europa de Edad Moderna. Ni Hintze ni los historiadores políticos han demostrado demasiado interés en los detalles de la transformación militar, contentos con identificar el cambio general de hueste feudal a ejército permanente como el catalizador de la mutación política. $\mathrm{La}$ «revolución militar» de Roberts permite superar esta limitación, ya que proporciona una interpretación detallada de los factores militares que justificaron la intensificación de la guerra y el crecimiento de los ejércitos.

La interpretación de la transformación militar que ofrece Roberts es, de hecho, un relato tradicional de los cambios tácticos en los ejércitos europeos, basado en las

11. LANE, F.: «Economic Consequences of Organized Violence», Journal of Economic History 18, 1958, pp. 401-17; Lane, F.: «The Economic Meaning of War and Protection» en Lane, F.: Venice and History. Baltimore Md, 1966. Esta idea se critica directamente en: Tilly, C.: «War Making and State making as Organized Crime» en Evans, P. B., Rueschemeyer, D. y Skocpol, T. (eds.): Bringing the State Back In. Cambridge, 1985, pp. 169-91, crítica en pp. 175-180.

12. Wood, J.: The King's Army. Warfare, Soldiers and Society during the Wars of Religion in France, 1562-1576. Cambridge, 1996, pp. 38-41. Esto fue característico de muchos estados fuera de Europa. En el caso del imperio véase: KolfF, D.: Naukar, Rajput and Sepoy. The ethnobistory of the military labour market in Hindustan, 1450-1850. Cambridge, 1990, pp. 32-116; Gommans, J:: Mughal Warfare. Londres, 2002, pp. 67-97; ZüRCHER E. J.: Fighting for a Living. A Comparative History of Military Labour, 15002000 (Amsterdam, de próxima publicación. Ofrecerá una buena reflexión sobre el reclutamiento). 
reformas castrenses realizadas por los Orange-Nassau en la República de Holanda y por el rey Gustavo II Adolfo de Suecia. El problema que hay con las guerras del siglo xvi, según su argumento, es que las fuerzas a menudo se hallaban demasiado igualadas en cuanto a número, tecnología y organización para poder lograr una victoria decisiva en el campo de batalla. Sin un elemento táctico decisivo, el arte de la guerra se estancó y los conflictos se convirtieron en combates sencillos, en los cuales, como dijo un contemporáneo, «la victoria se adjudica a aquel que posee el último escudo» que cada vez más conllevaba la ruina económica y, a veces, la «bancarrota» para todos los contrincantes ${ }^{13}$.

En contraste con este estancamiento, aparecían ideas ampliamente difundidas y, por tanto, aceptadas, de que el ejército de las Provincias Unidas había sido transformado por una adopción rigurosa y sistemática de las prescripciones militares de Eliano el Táctico, Vegecio y otros escritores militares clásicos, lo que permitía superar los males de indisciplina, alto mando descoordinado, y táctica burdas, tan presente en los ejércitos contemporáneos, y así convertir a los holandeses en «quizás en la más eficiente y seguramente la más imitada fuerza armada de su tiempo» ${ }^{14}$. Este modelo holandés consistía en filas de infantería más compactas, que aprovechaban mejor la potencia de mosquetes, ofrecían mayor flexibilidad e integraban mejor la caballería y artillería. El resultado era una notable innovación que daba mayor eficacia a los ejércitos en batalla, y diversas versiones fueron adaptadas en otros ejércitos. Con el desarrollo e imposición del orden cerrado se suplantó la destreza del combatiente individual con el orden colectivo y mecánico y la obediencia ${ }^{15}$. Estas transformaciones tácticas y organizativas dieron pie a la posibilidad de implementar una estrategia de aniquilación basada en la «batalla decisiva». La eficacia de esta estrategia requería ejércitos considerablemente más numerosos, lo que requería perfeccionar los sistemas logísticos, los mecanismos de reclutamiento, así como la gestión de los recursos humanos y materiales necesarios para sostener este nuevo impulso bélico. Esta estructura sería realizada por la intervención directa de un Estado de índole centralizador y burocrático. Con esto, desde un conjunto específico de transformaciones y desarrollo militar, el argumento de Roberts regresaba a una tradicional interpretación de la formación

13. Parker, G.: The Military Revolution. Military Innovation and the Rise of the West, 15001800. $2^{\mathrm{a}}$ ed; Cambridge, 1996, pp. 61-64.

14. FELD, M.: «Middle class society and the rise of military professionalism: the Dutch army, 1589-1609», Armed Forces and Society, 1 (1975), p. 421.

15. Feld, «Middle Class Society», pp. 419-42; WIJN, J. W.: Het krijgswezen in den tijd van Prins Maurits. Utrecht, 1934; Hahlweg, H.: Die Heeresreform der Oranier und die Antike. Berlin, 1941; Hahlweg, W. (ed.): Die Heeresreform der Oranier: das Kriegsbuch des Grafen Johann von NassauSiegen. Wiesbaden, 1973; Parker, G.: «The Limits to Revolutions in Military Affairs: Maurice of Nassau, the battle of Nieuwpoort (1600) and the Legacy», Journal of Military History, 71 (2007), pp. 331-372 y 366-369. 
de un Estado moderno, pero de una manera que supuestamente incentiva una forma específica de organización militar. Discutida, redefinida y abiertamente impugnada, la tesis de la «revolución militar» tiene, no obstante, una influencia extensa en la percepción de la historia de la Edad Moderna. Aun cuando el énfasis historiográfico se traslade a otras innovaciones tecnológicas, como mejoras en la construcción defensiva o en las tácticas de asedio, y cuando la cronología se matice o se cuestione, la tesis de Roberts sigue siendo el referente para la multitud de libros y artículos que traten específicamente de la relación entre la «revolución militar» y el crecimiento del Estado moderno ${ }^{16}$.

Desde el punto de vista de los argumentos que esgrimimos en The Business of War, el factor decisivo es cómo la «revolución militar» refuerza la premisa de que un ejército disciplinado, ordenado y efectivo requiere un control estatal directo sobre su reclutamiento, organización y mantenimiento. El Estado, se argumenta, ha de comprometerse a una inversión a largo plazo en la formación de la mano de obra militar entrenada y disciplinada. Semejante transformación se supone incompatible con las perspectivas a corto plazo del contratista militar privado, quien opera bajo su propia autoridad y se preocupa únicamente de conseguir unos rendimientos claros por las inversiones hechas en su tropa y negocio. Del mismo modo, el «flujo» del aprovisionamiento, equipamiento y logística deben dirigirse siempre hacia el mismo control administrativo directo, para así, supuestamente, reducir la ineficacia, la corrupción y los intereses divergentes que devienen de la contratación en el sector privado.

Lo que ha mermado las certezas deterministas de esta imagen de la marcha inexorable hacia la centralización militar y el control estatal, paradógicamente no ha sido una reevaluación del papel del sector privado en esferas militares. En realidad, ha resultado esencial para esta reevaluación el creciente escepticismo sobre el poder y eficacia del Estado en la Edad Moderna. Esta reinterpretación ha requerido un esfuerzo historiográfico prolongado durante casi cuatro décadas. Inicialmente se enfocó en el concepto de «Estado absolutista», con su supuesta concentración de poder coercitivo y autoridad en las manos del gobernante, una administración burocrática, responsable y profesional, y un ejército permanente formado y mantenido por dicha administración ${ }^{17}$. Se ha aplicado posteriormente con la misma facilidad

16. Véase especialmente: McNeILl, Pursuit of Power, pp. 117-43; Downing, Military Revolution; CoRnetTe, J.: «La révolution militaire et l'état moderne», Revue d'histoire moderne et contemporaine, 41 (1994), pp. 698-709; PORTER, B.: War and the Rise of the State. The Military Foundations of Modern Politics. Nueva York-Ontario, 1994.

17. Asch, R. y Duchhardt, H. (eds.): Der Absolutismus - ein Mythos? Strukturwandel monarchischer Herrschaft. Colonia, 1996; Henschall, N.: The Myth of Absolutism. Change and Continuity in Early Modern European Monarchy. Harlow, 1992; MetTam, R.: Power and Faction in Louis XIV's France. Oxford, 1988. 
a otros estilos de gobierno de la Edad Moderna. Sin embargo, posteriores estudios han subrayado la persistente debilidad y el limitado alcance del Estado, incluso en aquellos casos en los que estaba en manos de un gobernante indiscutido o una oligarquía que ofrecía una estrecha cooperación. En asuntos como la imposición de uniformidad religiosa, el mantenimiento del orden social, la regulación de la economía, la censura y el control de opinión pública, los gobiernos o bien cedieron y negociaron el apoyo popular de sus iniciativas, o bien fallaron en el intento de conseguir más que una fracción de sus objetivos pretendidos ${ }^{18}$. Lejos de estar a la vanguardia del «estado policial bien ordenado», el gobierno y sus administradores en la Europa de la Edad Moderna permanecieron reducidos, ya sea absolutamente o funcionalmente, $\mathrm{y}$ limitados en alcance, capacidad y ambiciones.

Que las iniciativas y políticas pretendidas por los gobiernos europeos en la Edad Moderna no fuesen una parca letanía de fracaso, inercia y confrontación ha sido atribuido a un modelo alternativo, el del gobierno por consenso, concesión y colaboración. Este modelo ha ganado, desde los años 80 , una creciente presencia en la historiografía de la política en la Edad Moderna. Los gobiernos europeos y sus estados aparecen en esta nueva revisión historiográfica funcionando dentro de las estructuras existentes de poder e influencia de la elite, y no en contra de ellas ${ }^{19}$. Esta colaboración podría suponer la conducción de ciertas políticas en la dirección que satisfacía las aspiraciones de los grupos de elite locales o institucionales, sean estos sociales, financieros, religiosos o culturales. Asimismo, podría suponer unas garantías y la consolidación de los intereses más generales de la elite correspondiente, como el precio a pagar por su cooperación y apoyo activo para imponer las políticas deseadas -bien sean gravámenes más elevados, una guerra impopular, o el acatamiento religioso superficial, por ejemplo-al resto de súbditos del gobernante.

En realidad, estos ejemplos de gobernantes trabajando con, en vez de en contra, de los intereses de la elite política y social establecida, plantean otros problemas interpretativos. Lo más notable, en lo que concierne a aspiraciones bélicas, es reconocer que el establecimiento de conciertos o concesiones con los grupos de interés existentes en el Estado, que es el precio necesario para conseguir su respaldo para la implementación de políticas militares, no concuerda con nuestros conocimientos

18. Véase, por ejemplo, la visión de conjunto de BRADDICK, M.: State Formation in Early Modern England, c. 1550-1700. Cambridge, 2000, donde plantea las dimensiones sociales de la autoridad política en vez de las exclusivamente administrativas. Braddick subraya que las innovaciones en las organizaciones y prácticas gubernamentales ocurrieron mayoritariamente en las áreas en las cuales existió una agregación de intereses entre los grupos dominantes de la sociedad.

19. BeIK, W.: «Absolutism as Social Collaboration in Louis XIV's France», Past and Present, 188 (2005), pp. 195-224; Evans, R. J. W.: The Making of the Habsburg Monarchy 1550-1700. Oxford, 1979; MACKAY, R.: The Limits of Royal Authority. Resistance and Obedience in Seventeenth-Century Castile. Cambridge, 1999. 
sobre muchos estados europeos que, a finales del siglo Xvil, ya habían conseguido incrementar impresionantemente sus habilidades en sustraer recursos financieros de sus súbditos y gastarlos en hacer la guerra ${ }^{20}$. Este dilema pone de manifiesto un cambio notable en la concepción de la naturaleza del poder de Estado de la Edad Moderna, y puede resumirse en la permutación léxica de «Estado absolutista», con sus presunciones sobre el nivel general de máxima autoridad y poder represivo en manos del gobernante, a un más extendido uso del término «Estado fiscal-militar» en un contexto de la Edad Moderna. Este concepto del «Estado fiscal-militar» llega al fondo de un sistema de gobierno cuyas prioridades están enfocadas en un propósito fundamental: la eficiencia en la recaudación -y gasto- de fondos para alcanzar los objetivos militares del Estado.

Precisamente porque levantar y mantener unas fuerzas armadas se identificaba como la principal preocupación y prioridad del gobierno y sus administradores esos sistemas políticos que aparentan estar plagados de exenciones y privilegios fiscales, intereses institucionales e individuales, corrupción y patrimonialismo pueden aguantar lo que parecen ser insoportablemente pesados y extensos costes militares. Hasta el día de hoy, la mayoría de los detallados estudios relacionados con el Estado fiscal-militar han buscado examinar las formas en que los gobernantes dirigían su limitada autoridad política y administrativa para maximizar los recursos financieros disponibles para la actividad militar. En muchos casos, conseguir estos recursos financieros se hizo a cambio de hacer permanentes el refuerzo y la estabilidad de los derechos, patrimoniales o políticos, de la elite ${ }^{21}$. No obstante, como ha recalcado notablemente Rafael Torres Sánchez en la introducción a una importante serie de estudios sobre el Estado fiscal-militar, la cuestión de cómo de eficazmente se utilizaban los recursos financieros para mantener el impulso militar merece parte de la atención previamente dedicada a la obtención de los fondos ${ }^{22}$. En este contexto, la manera más eficiente de optimización de recursos, la empresa militar y la contratación de empresarios ocupa mucho más que el puesto marginal que las teorías convencionales sobre la formación del Estado quieren adjudicarla.

En vez de ser un salto atrás al mundo pre-moderno de condotieros y vasallos militarizados «sobre-poderosos» -un proceso de «refeudalización»- las implicaciones de la dependencia entera o parcial en fuerzas armadas contratadas se

20. Brewer, J.: The Sinews of Power: War, Money and the English State, 1688-1783. Londres, 1989; Rowlands, G.: The Financial Decline of a Great Power. War, Influence and Money in Louis XIV's France. Oxford, 2012, especialmente la primera parte, sobre recursos y gestión financiera.

21. Algunos ejemplos desde el punto de vista francés: Beır, W.: Absolutism and Society in Seventeenth-Century France: State Power and Provincial Aristocracy in Languedoc. Cambridge, 1985, pp. 245-278; Rоот, H.: The Fountain of Privilege. Berkeley Ca, 1994, pp. 23-40; РотTER, M.: Corps and Clienteles. Public Finance and Political Change in France. Aldershot, 2003, pp. 3-25.

22. Torres Sánchez, War, State and Development, pp. 14-44. 
convirtió en el eje de la capacidad de movilización militar del Estado fiscal-militar. El empresario militar fue esencial en las guerras llevadas a cabo por estados cuyas capacidades administrativas y organizativas quedaban extremadamente limitadas, y que dependían de otros medios para plasmar la cooperación y cumplir con los intereses de la elite política y económica. Para demostrar esto claramente se requiere una perspectiva más extensa y equilibrada de las funciones de las empresas militares, al menos más de lo que permitían las interpretaciones tradicionales, distorsionadas por paradigmas anti-mercenarios y concepciones deterministas sobre la evolución del Estado y la revolución militar.

La necesidad de reevaluar los empresarios militares y sus métodos bélicos en la Edad Moderna es lo que The Business of War intenta ofrecer, al menos grosso modo. Esta necesidad de reinterpretación es más obvia en lo referente al periodo de 1550 a 1650, cuando los desafíos para mantener unas fuerzas militares hasta entonces desconocidas cayeron sobre estados y gobernantes, con posibilidades muy limitadas de sacar los recursos financieros necesarios de sus súbditos y que dependían acuciantemente de la cooperación de la elite. En este contexto de un Estado con poderes débiles y recursos limitados, el florecimiento de la empresa militar puede parecer la «primera fase» en la formación del Estado fiscal-militar, una fase de «devolución militar».

Por muchas razones, desde mediados del siglo XvI, la duración de los periodos bélicos comenzó a incrementarse significativamente. Desde las guerras europeas del siglo anterior, que aunque llegasen a disputarse en escalas considerables raramente duraban ininterrumpidamente más de una o dos campañas, a las campañas españolas en los Países Bajos a partir del 1568 y la Gran Guerra Turca de 1593 a 1606, se plasmó la idea de que las guerras ya tenían el potencial de continuar durante muchos años, cuando no décadas. Los condotieros italianos o los capitanes mercenarios suizos de los siglos Xv y xvI habían reunido tropas bajo la previsión de que el conflicto sería breve y mínimas las oportunidades de extender beneficios de la gestión de las unidades militares. Los capitanes mercenarios simplemente negociaban un pago cuantioso adelantado con la autoridad, con la idea de cubrir los costes tanto de reclutamiento como de operación y sacar un beneficio neto gracias al ahorro en gastos de administración, saqueo o cualquier pago adicional que pudiera sumarse antes de que la unidad fuese desmovilizada ${ }^{23}$. Pero como la duración de la guerra se extendía, aquellos que llegaban a ser empresarios militares podían pensar en diferente forma acerca de la inversión de capital y riesgo.

23. Mallett, Mercenaries, pp. 113-14; Blastenbrei, P.: Die Sforza und ibr Heer. Studien zur Strukture-, Wirtschafts- und Sozialgeschichte des Söldnerwesens in der italienischen Frübrenaissance. Heidelberg, 1987, pp. 50-60; Burin De Roziers, M.: Les Capitulations militaires entre la Suisse et la France. Doctorate, París, 1902; Schaufelberger, W.: Der Alte Schweizer und sein Krieg. Studien zur Kriegsfübrung vornehmlich im 15. Jahrhundert. Zúrich, 1952. 
Esto señala el nacimiento del coronel-propietario, dispuesto a comprometerse a grandes inversiones en la formación y operación de su regimiento, o regimientos. Comparando los regimientos alemanes que servían en el ejército español en Flandes después de 1570 con sus predecesores en las guerras italianas se pone de relieve hasta qué punto el nivel de compromiso económico de los comandantes se incrementó exponencialmente ${ }^{24}$. Para finales del siglo XVI, los coroneles-propietarios estaban subvencionando el reclutamiento de las tropas, su equipamiento y hasta la organización de subsistencia cuando era necesario ${ }^{25}$. La exigencia de un pago adelantado fijo al contratar con el Estado fue abandonada en favor de una remuneración a largo plazo, ya sea en entregas regulares y elevadas al propietario del regimiento, o bien en la oportunidad de exigir o recaudar impuestos y botines, año tras año. A la larga, fueron las recaudaciones y botines los que servirían principalmente para recompensar las inversiones de capital iniciales y posteriores, generar beneficios o cubrir los intereses devengados, así como el pago de la deuda principal a aquellos que habían concedido créditos a los contratistas, porque detrás de los coroneles se formaba una extensa retahíla de promotores e inversores. En muchos casos, el propietario del regimiento o regimientos no era quien actuaba de comandante en el campo, sino una red de acreedores que se extendía por todo el sistema de financiación de todos los ejércitos contratados ${ }^{26}$. Más aún, el ejército contratado buscaría fuentes externas para abastecerse de comida, armas, equipamiento y municiones en mercados y redes internacionales, integradas por proveedores, fabricantes y transportistas especializados. En los casos donde escuadrones navales eran gestionados bajo contrato, suministros y mantenimiento de astilleros podía también ser contratado fuera, en otras cadenas de contratistas igualmente extensas ${ }^{27}$. La organización de los pagos de intereses y la amortización de los préstamos estaban en las manos de los empresarios militares, una vez que el Estado les autorizaba a recaudar y distribuir las contribuciones, o asignaba rentas o dinero efectivo para cubrir los gastos ${ }^{28}$.

Hacia la Guerra de los Treinta Años los contratistas militares estaban sensibilizados con la idea de que las unidades militares podían ser formadas y gestionadas

24. Baumann, R.: Georg von Frundsberg. Múnich, 1991, pp. 260-261; RedLich, Military Enterpriser, i., pp. 74-75 y 88-89.

25. Welti, L.: Graf Jakob Hannibal I. von Hohenems, 1530-1587. Ein Leben im Dienste des Katholischen Abendlandes. Innsbruck, 1954, pp. 184-191; ZwIEDINECK-SüDENHORST, H. von: Kriegsbilder aus der Zeit der Landsknechte. Stuttgart, 1883; PArker, G.: The Army of Flanders and the Spanish Road, 1567-1659. Segunda edición, Cambridge, 2004, pp. 190-191.

26. ZwiedineCK-SüDENHORST, Kriegsbilder, pp. 231-234.

27. Por el ejemplo de las galeras genovesas organizadas en nombre de la Corona española, véase: Kirk, T.: Genoa and the Sea. Policy and Power in an Early Modern Maritime Republic, 1559-1684. Baltimore-Londres, 2005; Thompson, War and Government, pp. 163-184.

28. Parker, Army of Flanders, pp. 120-123. 
como inversiones a medio o largo plazo, con la posibilidad de producir beneficios durante un periodo notable de años, ya sean cinco, diez o más. Incluso cuando los mercenarios se licenciaban, como fue el caso con muchas de las unidades imperiales después de la dimisión de Wallenstein por el Emperador en 1630, los mismos coroneles-propietarios se ofrecieron para volver a formar las unidades en 1631, cuando al Generalisimo se le permitió comenzar su segundo mandato ${ }^{29}$. Todos los grandes ejércitos en esa guerra ofrecen ejemplos de regimientos levantados por empresarios para periodos largos; en los casos de los ejércitos bávaros e imperiales algunos de estos estaban formados desde $1620^{30}$.

La combinación de la transferencia de los costes de reclutamiento y mantenimiento de tropas constituidas por decenas de miles de soldados, junto con la expansión y variedad de contratos de abastecimiento, de fabricación y provisión de armas y de transporte, liberaba un gran sector de la actividad militar del Estado. Gran parte de esos negocios se financiaban a base de capital obtenido con mejores tipos de interés que los que podrían haber conseguido los gobernantes y la administración; en muchos casos, no se podría ni siquiera haber conseguido préstamos si hubiera dependiendo de la solvencia del Estado. La condición en este sistema es que semejantes rendimientos a largo plazo para los empresarios y sus colaboradores solo sería interesante si los regimientos, como componentes del ejército más amplio, no tenían que ser reconstruidos completamente, y costosamente, cada campaña o dos. Hasta cierto punto esto correspondía a los coroneles, quienes tenían que comprometerse al gasto inicial y más oneroso de contratar y mantener soldados con experiencia, veteranos, quienes serían más propensos a quedarse en la tropa y considerar el ser mercenario como una profesión ${ }^{31}$. Más aún, la manera en que se abordaban las campañas requería el reconocimiento de que las unidades de un ejército formaban una inversión valiosa, y no podían ser desperdiciadas en operaciones caprichosas, mal planeadas o militarmente inútiles. Esto no significaba la adopción de una política de pasividad militar, con la mera ocupación de territorio y la extorsión de recursos a los habitantes. Ganar la iniciativa militar, ya sean en términos de ventajas operacionales, control territorial o la seguridad de líneas de comunicación y abastecimiento, tenía una correlación directa con el bienestar económico del ejército y, por tanto, con el de

29. Heilmann, J.: Das Kriegswesen der Kaiserlichen und Schweden zur Zeit des Dreißigjährigen Krieges. Leipzig, 1850 -reimpreso en Krefeld, 1977-, pp. 156-157; Konze, F.: Die Stärke, Zusammensetzung und Verteilung der Wallensteinischen Armee während des Jabres 1633. Ein Beitrag zur Heeresgeschichte des 30 Jährigen Krieges. Dissertation: Frankfurt-am-M, 1906, pp. 19-22, pp. 26-35.

30. Heilmann, J.: Kriegsgeschichte von Bayern, Franken, Pfalz und Schwaben von 1506-1651, 2 vols.; Múnich, 1868, ii. pp. 902-906; los números de Redlich demuestran que más de una tercera parte de los regimientos estuvieron formados durante seis años o más, con una proporción muy grande de los restantes con tiempos de dos a cinco años: Military Enterpriser, i. p. 226.

31. Parrott, Business of War, pp. 158-162. 
los contratistas militares. Con ella, se incrementaban las posibilidades de extraer recursos de un territorio más amplio, se estimulaba la concesión de más crédito, y se afianzaba la posibilidad de conseguir un acuerdo final de paz en el cual las deudas de los contratistas serían plenamente reconocidas.

Aun así, en notable contradicción a las premisas de la «revolución militar», ganar la ventaja militar no significaba lanzar ejércitos inmensos a una batalla cruenta e impredecible, tan catastrófica que destruyera la posibilidad de que incluso el ejército vencedor pudiera alcanzar sus objetivos operacionales. Todavía menos interesante era emprender enormes sitios en poblaciones o plazas principales, que, de hecho, se convertían en la mejor forma existente para malgastar un ejército y despilfarrar los meses de campaña.

Aunque a la Guerra de los Treinta Años a menudo se le da un carácter cronológico formado de batallas campales y asedios, buena parte de este conflicto se llevó a cabo desde el principio al estilo de conflictos «irregulares»: pequeñas tropas, muchas veces luchando por el control local, sin los recursos necesarios para emprender asedios de gran envergadura y evitando batallas, salvo en circunstancias inminentemente favorables. Este tipo de combate, que enfatizaba la movilidad, la flexibilidad en concebir y cambiar objetivos operacionales, el control o la denegación territorial, pero sin malgastar grandes recursos en asedios o entrar en luchas indeseadas, se adoptó cada vez más, a lo largo de toda la cadena de mando y con fuerzas relativamente más numerosas. En 1632, Pappenheim realizó una campaña irregular y altamente exitosa en Westfalia, con tropas móviles, experimentadas y resistentes, de entre 5.000 y 10.000 hombres, desplegadas contra las fuerzas suecas y alemanas tres o cuatro veces más numerosas, que empleaban la táctica más tradicional de saturación y ocupación territorial practicada por Gustavo II Adolfo después de su victoria en Breitenfeld ${ }^{32}$. Este estilo «irregular» se convertiría cada vez más en el patrón escogido de táctica bélica, de muy perceptible evolución durante la segunda mitad de esta guerra, manejado por una serie de empresarios-comandantes militares quienes eran muy conscientes de las fuerzas y debilidades de sus hombres y, en consecuencia, de las prioridades necesarias. Indistintamente desarrollada por los comandantes suecos como Banér, Torstensson y Wrangel, o sus aliados franceses en Alemania, Guébrant y Turenne, o sus adversarios imperiales y bávaros como Hatzfeld, Melander y Mercy, todos intentaban emplear esta propuesta más económica y operativamente más sofisticada.

Por debajo de la propuesta estratégica había una preocupación por la sostenibilidad. Una estrategia que lograba un objetivo único, por ejemplo, la toma de una

32. Stadler, B.: Pappenheim und die Zeit des Dreißigjährigen Krieges. Winterthur, 1991, pp. 603-714; KaIser, M.: «'Sed vincere sciebat Hanibal'. Pappenheim als empirischer Theoretiker des Krieges» en Neuhaus, H. y Stollberg-Rilinger, B. (eds.): Menschen und Strukturen in der Geschichte Alteuropas. Berlín, 2002, pp. 201-227, pp. 219-223. 
ciudad después de un asedio prolongado, pero que en el proceso había agotado el ejército o lo había dejado incapaz de perseguir nuevos objetivos de la campaña, se podría considerar un fracaso militar y arriesgaba perder la confianza y apoyo de los contratistas que eran socios en la empresa militar. Para estos comandantes, conseguir que el ejército siguiera en pie era una precondición para el éxito operacional. Esto quería decir, sobre todo, la conservación del elemento clave para su poder de ataque: el núcleo de soldados veteranos quienes habían adoptado la vida soldadesca como profesión permanente, quienes aceptaban las dificultades de la vida en campaña y quienes poseían la fortaleza física, psicológica y castrense para luchar, ya sea en las filas ordenadas del campo de batalla, el tumulto de una carga de caballería en terreno abierto o la defensa de una plaza fuerte aislada. Hay que insistir en que la eficacia de estos ejércitos no se debía a su supuesta adherencia a un despliegue táctico y organizativo innovador, sino a la presencia de tropas veteranas y experimentadas. Como ya se indicó, ellos eran el corazón de la inversión hecha por los coroneles-propietarios, con la que se alcanzaba la eficacia de sus regimientos. El mantenimiento de los regimientos como inversiones a medio o largo plazo aseguraba la formación de lo que solía ser una reserva creciente de estos veteranos de servicio dilatado. Hacia la década de 1640, los regimientos bávaros se formaban de un casi $60 \%$ de tropas con experiencia probada en varias campañas ${ }^{33}$.

Los comandantes confiaban en ejércitos más reducidos, pero que contaban con un alto porcentaje de estas tropas experimentadas. Alrededor de este núcleo se podían colocar los nuevos reclutas al inicio de cada campaña, sin tener que hacer la misma inversión para conservarles entre las filas: una pequeña proporción se quedaría y adquiriría experiencia castrense -y, así, un valor para el empresario-, la mayoría desertaría o caerían enfermos, habiendo sido reclutados por poco dinero y mal retribuidos, o no pagados. Estos ejércitos reducidos y más móviles emprendían operaciones que no perseguían batallas deliberadamente «decisivas», sino más bien se dedicaban a reducir el territorio en manos del enemigo o a la destrucción de los recursos de este: respondiendo con rapidez para separar una tropa enemiga de sus bases de apoyo o utilizar la sorpresa y la devastación para capturar territorio y extraer recursos o pedir rescate. Las campañas del general sueco Johan Banér, al final de la década de los 1630, nos proporciona un ejemplo magistral de tales estrategias operacionales, no menos por ser Banér quien había sido tan decisivamente superado tácticamente mediante la misma clase de estrategia practicada por Pappenheim en $1632^{34}$. La preocupación consistía en lograr estos resultados sin sufrir un elevado índice de desgaste, lo que suponía en primer y

33. KaPSER, C.: Die bayerische Kriegsorganisation in der zweiten Hälfte des Dreißigjährigen Krieges. Münster, 1997, pp. 262-264.

34. BJörLin, J. G.: Johan Banér, 3 vols.; Estocolmo, 1908-1910. 
principal lugar no adelantar demasiado al apoyo logístico. Mantener abastecidas a las tropas dependía de un delicado equilibrio entre una cuidadosa planificación y la improvisación. Para aquellas, las relaciones estrechas entre el contratista y los proveedores de víveres, municiones y crédito eran vitales para poder organizar, muchas veces con poca antelación, las reservas de suministros y transportes, todo programado para reunirse con el ejército donde se encontrara en el campo ${ }^{35}$. La habilidad de los empresarios militares de aprovechar una red internacional de producción, abastecimiento y transporte más flexible y extensa que cualquiera que pudiera haber proporcionado el Estado es aquí fundamental. Integrándose en redes de comercio y producción, que se basaban en relaciones personales de largo alcance, altos grados de confianza y sistemas establecidos de crédito y movilización de recursos, había muchas más posibilidades de garantizar un nivel efectivo de apoyo para sus operaciones militares ${ }^{36}$. Los contratistas militares al mando del Ejército Imperial hacia 1640, por ejemplo, utilizaron los recursos obtenidos en Baja Renania-Westfalia para financiar las operaciones de los ejércitos imperiales en el campo, cuyos comandantes construyeron un sistema de estrechos vínculos personales con los proveedores de víveres y municiones de la región, además de relaciones, de no menos importancia, con consorcios y redes que operaban por todo el sur de Alemania y cruzaban las fronteras de Flandes y Lieja ${ }^{37}$. Cuando estos acuerdos y vínculos iban acabándose, lo que era casi inevitable, los suministros solo podían complementarse mediante requisas y saqueos. Esto último fue posible porque se trataba de ejércitos que normalmente eran mucho más reducidos que los que se formaron al iniciarse la Guerra de los Treinta Años, en la etapa de Wallenstein y Gustavo II Adolfo, cuando había una mayor presencia de caballerías e infanterías montadas con mayor movilidad y que podían recorrer más terreno en búsqueda de comida y forraje ${ }^{38}$.

Debido a que se puso el énfasis en los enfoques tácticos, que reclamaban el control y exclusión territorial, y dada la calidad de las tropas en ambos ejércitos,

35. Pappenheim se describe con un sentido/comprensión real de las necesidades de abastecimiento de sus tropas «Fürsorgesinn», crucial para desempeñar el papel de un comandante eficaz en la Guerra de los Treinta Años: Stadler, Pappenheim, p. 693.

36. Para un trabajo clave en el desarrollo de estas organizaciones véase: ZuncKEL, J.: Rüstungsgeschäfte im Dreißigjäbrigen Krieg: Unternehmerkräfte, Militärgüter und Marktstrategien im Handel zwischen Genua, Amsterdam und Hamburg. Berlín, 1997. La obra clásica de ErnstBerger, A.: Hans de Witte - Finanzmann Wallensteins, Wiesbaden, 1954, proporciona todavía uno de los mejores estudios de casos de una red compleja y privada de abastecimiento.

37. SAlm, H.: Armeefinanzierung im Dreißigjährigen Krieg. Die Niederrheinisch-Westfälische Reichskreis, 1635-50. Münster, 1990; KREBs, J.: Aus dem Leben des kaiserlichen Feldmarschalls Grafen Melchior von Hatzfeld, 1593-1636, 2 vols.; Breslau, 1910, 1926.

38. Sörensson, P.: «Das Kriegswesen während der letzten Periode des Dreißigjährigen Krieges» en Rudolf, H.: (ed.). DerDreißigjährige Krieg. Perspectiven und Strukturen. Darmstadt, 1977, pp. 431-457. 
las batallas como Breitenfeld II (1642), Jankow (1645) y Allerheim (1645) resultaron duros combates y sangrientos, con bajas extremadamente elevadas en ambos lados $^{39}$, pero, y esto es lo importante, tales batallas raramente ofrecieron resultados sustanciales y duraderos para los vencedores, como mucho, ayudaron a equilibrar o inclinar la balanza de ventajas tácticas adquiridas en una campaña particular en favor de uno de los dos combatientes, lo que se podría haber logrado por otros medios. Esto era lo que la mayoría de los comandantes sospechaba y sabía, por lo que la mayor parte quisieron evitar la baja de soldados experimentados en el campo de batalla, que siempre daba un resultado final menos ventajoso que tácticas que primaran el movimiento, las emboscadas y la ocupación territorial. Era este equilibrio entre los ejércitos y el control terrestre, lo que explica por qué, aun con el deterioro gradual de las posiciones imperiales evidente después de 1645 y la victoria sueca en Jankow, los ejércitos del Emperador y sus contratistas continuaron combatiendo, y los financieros y proveedores siguieron concediéndoles crédito. Se podría sostener que los ejércitos de la última etapa de la Guerra de los Treinta Años tardía fueron unos de los instrumentos militares más rentables (costeeficacia) y bien ajustados de la Edad Moderna. La razón principal de por qué la guerra duró tanto no fue el estancamiento militar, sino el despliegue competente de ejércitos veteranos eficaces y experimentados, reclutados y mantenidos por contratación privada, cuya movilidad y eficacia impedía que ninguna potencia ganara la supremacía.

No debería ser asumido, por lo tanto, que la Guerra de los Treinta Años puso a prueba hasta la destrucción un sistema imperfecto de contratación y suministro privado de fuerzas armadas, lo que justificaría la reacción inevitable en la siguiente etapa como un paso decidido hacia el control estatal del «monopolio de violencia». En realidad, mucho se podría añadir sobre la fuerte continuidad en las relaciones Estado-Ejército, en el deliberado mantenimiento de los sistemas que dependían intensamente del sector privado por su capital, experiencia y organización. De hecho, después de 1650, comienza lo que podemos llamar una «segunda fase» en el desarrollo del Estado fiscal-militar, vista a través de modificados mecanismos del espíritu empresarial militar y la contratación privada. La mayoría de los estados se alejaron del uso global de la contratación militar, que previamente había servido como escapatoria de una administración estatal inadecuada e ineficaz y la debilidad fiscal, y se sustituyó a finales del siglo xviI, no con un ejército permanente bajo el control del Estado, sino con un modelo abiertamente más colaborativo para la movilización de recursos militares. En muchos estados se desarrollaron sistemas

39. Wilson, P.: Europe's Tragedy. A History of the Thirty Years War. Londres, 2009, da detalles y bajas de estas batallas. Véase también Guthrie, W.: The Later Thirty Years War. From the Battle of Wittstock to the Peace of Westphalia. Westport/Londres, 2003. 
mayores y más regulares de distribución de finanzas estatales, con aumento del control administrativo, y mejor capacidad para la determinación de políticas militares y la imposición de una autoridad militar, y todo esto fue compatible con la continuidad del papel financiero y organizativo de oficiales militares y una creciente dependencia de la contratación externa privada de funciones de abastecimiento, manufacturación y logística militar ${ }^{40}$.

En algunos estados el interés capitalista de los oficiales de unidades militares encontró su expresión en un reforzado sistema de venalidad, que subrayaba que el oficio en sí mismo, y no la unidad de soldados, era propiedad del oficial ${ }^{41}$. Así, el oficial tenía un interés económico en la calidad militar y hasta en la apariencia física de su unidad, porque tendrían un impacto directo en el valor comercial de la unidad, a tiempo que servían como una fuente de prestigio personal. Un ejército constituido por unidades que se consideraban de duración extendida o permanente sería más eficaz en conseguir recursos privados de estos oficiales para mejorar y mantener sus inversiones iniciales. En recompensa por las inversiones de entrada, se les podría permitir al coronel, o últimamente al capitán, tomar parte en el «negocio de la unidad»-la inversión y recuperación de capital mediante la provisión de equipamiento, uniformes y a veces hasta la comida de sus soldados- o, como es sabido en el caso de la armada holandesa, sus marineros ${ }^{42}$.

Permitir este «negocio» no era una anticuada concesión a una elite privilegiada, hecha a regañadientes dentro de unas organizaciones militares racionales y centralizadas. En realidad, se trataba de un precondición esencial de la eficacia de organizaciones militares que necesitaban «inversiones de socios» en igual medida que antes. Sin embargo, ahora la integración del socio se canalizaba por vías menos arriesgadas para los empresarios (evitando múltiples contrataciones de regimientos, por ejemplo), y más manejables en el contexto de ejércitos que permanecían relativamente grandes en tiempos de paz, cuando las oportunidades

40. En Francia, las reformas de los ministros de Guerra Michel Le Tellier y su hijo el Marqués de Louvois han sido desde hace mucho identificadas con un programa semejante: RousseT, C.: Histoire de Louvois et de son administration politique et militaire, 4 vols. París, 1879; ANDRÉ, L.: Michel Le Tellier et l'organisation de l'armée monarchique. París, 1906; Convisier, A.: Louvois, París, 1983. Véase la escueta crítica de esta posición en CHAGniot, J.: «La rationalisation de l'armée française après 1660» en Armées et diplomatie dans l'Europe du XVIIe siècle. Actes du Colloque des Association des Historiens Modernistes. París, 1991, pp. 97-108.

41. Rowlands, G.: The Dynastic State and the Army under Louis XIV. Royal Service and Private Interest, 1661-1701. Cambridge, 2002, pp. 166-171; DrÉvillon, H.: L'impot du sang: Le métier des armes sous Louis XIV. París, 2005, pp. 179-211; Снagniot, J.: Paris et l'armée au xviiie siècle. Étude politique et sociale. París, 1985, pp. 255-277.

42. Bruijn, J.: The Dutch Navy of the Seventeenth and Eighteenth Centuries. Columbia, SC, 1993, pp. 116-117. 
de encontrar otros medios de financiación, como botines y confiscaciones, no se toleraría ${ }^{43}$.

Aún hace falta mucha investigación sobre el «negocio de regimiento» de los siglos XVII y XVIII, la gestión de la propiedad, gastos y posibles beneficios alcanzados por los dueños de regimientos y compañías, quienes, de una manera u otra, continuaban llenando los altos escalafones de oficiales en los ejércitos europeos. Todavía conocemos poco sobre el «estado de cuentas» de los propietarios en la mayoría de estos ejércitos, pero sí sabemos que de una manera u otra el negocio de gestionar un regimiento fue una fuente legitima de ganancias, y también sabemos que la remuneración formal o informal era característica de la transferencia de cargos en los altos mandos de la mayoría de las organizaciones militares ${ }^{44}$. Hay muchas evidencias, anécdotas y memorias individuales que muestran que los comandantes de los regimientos sufragaban los costes de funcionamiento y mantenimiento de sus unidades hasta bien entrado el siglo xviII. No obstante, tratado como un remanente de un sistema desacreditado, que sería pronto eliminado, este asunto ha recibido poca de la atención que realmente merece. Sobre todo, cuando los historiadores de hoy en día están muchísimo más sensibilizados ante el estudio de las ventajas e intereses de los participantes en las relaciones entre las élites y el Estado de los siglos XVII y XVIII.

Un relato diferente y ahora mucho mejor desarrollado se presenta con el crecimiento del contratista de suministros militares en la segunda fase del Estado fiscal-militar europeo. En la medida que los ejércitos aumentaban dramáticamente a finales del siglo XVII, también se incrementaban las oportunidades para equiparar, abastecer, transportar y, a corto plazo, financiar las cada vez más numerosas tropas. Los contratos de suministros eran concedidos por el gobierno central o por sus agentes en el campo y, en ocasiones, por los comandantes delegados o comisionados a llevar a cabo los trámites necesarios. En todo caso, la respuesta abrumadora del Estado del Antiguo Régimen a la variedad de necesidades logísticas y operativas fue continuar e incluso expandir la delegación de esta organización a manos de fabricantes privados, proveedores, comerciantes y transportistas. Este hecho ha sido documentado por una generación de estudiosos y sus obras en general coinciden en destacar que la contratación externa de suministros y logística a contratistas privados fue una decisión completamente

43. El ejército bávaro era pionero en la prohibición de la posesión de más de un regimiento por el mismo propietario: KaISER, M.: Politik und Kriegsführung Maximilian von Bayern, Tilly und die Katholische Liga im Dreißigjährigen Krieg. Münster, 1999, pp. 69-70.

44. Las mejores obras sobre la propiedad de regimientos son las dedicadas al ejército británico: Bruce, A. P.: The Purchase System in the British Army, 1660-1871. Londres, 1980, y Guy, A.: Oeconomy and Discipline. Officership and Administration in the British Army, 1714-63. Manchester, 1985. 
racional, brindando ventajas en eficacia y flexibilidad a un precio competitivo y con una fiabilidad impresionante ${ }^{45}$.

La asociación activa e interesada entre los sectores públicos y privados fue el núcleo del Estado fiscal-militar, ya fuese mediante el mecanismo de venalidad o de otra forma de propiedad que pudiese convencer a la elite para invertir su capital en las unidades militares, o bien por la dependencia en la contratación de armamentos y abastecimiento que implicaron a las conexiones, organizaciones y recursos de una elite comerciante con afán de lucro, pero que funcionaba con una eficacia que la administración del Estado dificilmente podría haber conseguido. Visto en términos de estados cuyo raison d'être era la optimización de recursos militares, la supervivencia y prosperidad de estas asociaciones a lo largo del periodo del Antiguo Régimen no es sorprendente. Si reducimos la importancia de una interpretación predeterminada de construcción del Estado, estos mecanismos de movilización de recursos privados eran simplemente mejores, más flexibles y más preparados para maximizar las posibilidades militares del Estado que habría sido cualquier intento de implementar un control estatal directo y global. Lejos de quedarse relegado por la aparición de sistemas de administración militar centralizados y control estatal directo, la dependencia en la contratación e inversión por parte del sector privado continuó dominando los ejércitos del Antiguo Régimen.

Queda una pregunta obvia: ¿cómo explicamos la desaparición del empresario militar hacia finales del siglo xvIII? No parece que fuese un sistema que se fuera erosionando hasta terminar por ser irrelevante, pero sabemos que durante de las Guerras Revolucionarias Francesas se atravesó un umbral crítico. Los ejércitos mismos se habían convertido en empresas estatales, en los cuales los coroneles y capitanes ya no eran en absoluto considerados como empresarios en sus unidades. Los contratistas privados seguían en el suministro militar con frecuencia a regañadientes. Agentes y administradores militares eran ahora los encargados de requisar y negociar directamente los suministros necesarios para las fuerzas armadas.

La explicación obvia es que el nacimiento de la levée en masse y la nación en armas no dejó cabida para el contratista y el empresario. El servicio militar ahora se consideraba un deber sagrado del ciudadano, y fue impuesto por coerción como medio para levantar fuerzas sin precedentes en cuanto a número y cuyo impulso y sacrificio podrían sobreponerse a los ejércitos entrenados y disciplinados del Antiguo Régimen. Cualquier oportunidad de lucro, organización o contratación por parte del sector privado (aun cuando estos fueran soportes convenientes para la actividad militar) solo podía mancillar este deber sagrado de ciudadano de servir su nación en la guerra.

45. Véase el amplio abanico de estudios explorando el contratista militar indicado en la cita número 2 . 
No cabe duda que la considerable fuerza que hay en la ecuación de reclutamiento y nación en armas conlleva un distanciamiento consciente de toda actuación del empresario militar ${ }^{46}$. Aun así, desacreditar el sistema militar del Antiguo Régimen fue un asunto contingente: evitar la derrota en Valmy en 1792 confirmó lo que podría haberse visto en la posteridad como un intento desesperado y sin sentido del gobierno revolucionario. ¿Si la nación en armas hubiera fracasado en 1792, habrían continuado los empresarios y contratistas militares en su evolución habitual del Antiguo Régimen? Hay evidencias -e investigaciones más concretas son seguramente necesarias antes de llegar a cualquier conclusión definitiva- que sugieren que a partir de la década de 1760 se generalizaron en muchas sociedades europeas las críticas e insatisfacción hacia la contratación externa de las funciones de los ejércitos, tanto militares como de abastecimiento. Una creciente oposición publica a los contratistas militares, vistos a menudo como chivos expiatorios por fracasos militares, producía un clima político en el cual el «negocio de la guerra» fue mucho más difícil de mantener. Este descrédito de un sistema, que había ofrecido ventajas claras y consistentes en cuanto a créditos, flexibilidad y responsabilidad compartida, podría haber sido el factor más importante en la desaparición de la contratación privada en los ejércitos europeos durante un par de siglos.

El propósito principal de The Business of War, no obstante, es sumarse a las recientes iniciativas que pretenden remediar los primeros balances historiográficos, que durante demasiado tiempo han considerado el desarrollo de las instituciones militares en Europa durante la Edad Moderna desde la perspectiva constreñida de un monopolio creciente de poderes estatales centralizadores. Romper con este modelo determinista de la creación del Estado militarizado, y cuestionar aún más profundamente la idea de una «revolución militar» que subyace desde hace tanto tiempo, puede hacer posible una síntesis nueva y convincente del papel que han jugado las fuerzas armadas en los estados y sociedades de la Europa de la Edad Moderna.

\section{BibliografíA}

ANDRE, L.: Michel Le Tellier et l'organisation de l'armée monarchique, Paris, 1906.

Asch, R. H. y Duchinard, H. (eds.): Der Absolutismus - ein Mythos? Strukturwandel monarchischer Herrschaft, Köln, 1996.

Bannerman, G.: Merchants and the Military in 18th-Century Britain. British Army Contracts and Domestic Supply, 1739-1763, London, 2008.

46. Hippler, T.: Citizen, Soldiers and National Armies. Military Service in France and Germany, 1789-1830. Londres, 2008; Moran, D. y Waldron, A. (eds.): The People in Arms: Military myth and national mobilization since the French Revolution. Cambridge, 2003. 
Baumann, R.: Georg von Frundsberg, Munich, 1991.

BEIK, W.: «Absolutism as Social Collaboration in Louis XIV's France», Past and Present, 188 (2005), pp. 195-224.

http://dx.doi.org/10.1093/pastj/gti019

— : Absolutism and Society in Seventeenth-Century France: State Power and Provincial Aristocracy in Languedoc, Cambridge, 1985.

BJörLin, J. G.: Johan Banér, 3 vols.; Stockholm, 1908-10.

Blastenbrei, P.: Die Sforza und ibr Heer. Studien zur Strukture-, Wirtschafts- und Sozialgeschichte des Söldnerwesens in der italienischen Frübrenaissance, Heidelberg, 1987.

Bowen, H. y González Enciso, A. (eds.): Mobilizing Resources for War. Britain and Spain at Work during the Early Modern Period, Pamplona, 2006.

BRAdDICK, M.: State Formation in Early Modern England, c. 1550-1700, Cambridge, 2000.

Brewer, J.: The Sinews of Power: War, Money and the English State, 1688-1783, London, 1989.

Bruce, A. P.: The Purchase System in the British Army, 1660-1871, London, 1980.

Bruijn, J.: The Dutch Navy of the Seventeenth and Eighteenth Centuries, Columbia, 1993.

Burin De Roziers, M.: Les Capitulations militaires entre la Suisse et la France, Paris, 1902.

Chagniot, J.: «La rationalisation de l'armée française après 1660», en Armées et diplomatie dans l'Europe du Xvile siècle. Actes du Colloque des Association des Historiens Modernistes, Paris, 1991, pp. 97-108.

Chagniot, J.: Paris et l'armée au Xvirie siècle. Étude politique et sociale, Paris, 1985.

Conway, S. y Torres Sánchez, R. (eds.): The Spending of States. Military Expenditure during the Long Eighteenth Century: patterns, organization and consequences, 1650-1815, Saarbrücken, 2011.

CoRnetTe, J.: «La révolution militaire et l'état moderne», Revue d'histoire moderne et contemporaine, 41, 1994, pp. 698-709.

Corvisier, A.: Louvois, Paris, 1983.

Downing, B.: The Military Revolution and Political Change. Origins of Democracy and Autocracy in Early Modern Europe, Princeton, 1992.

Drevillon, H.: L'impot du sang: Le métier des armes sous Louis XIV, Paris, 2005.

Ernstberger, A.: Hans de Witte - Finanzmann Wallensteins, Wiesbaden, 1954.

Ertman, T.: Birth of the Leviathan. Building States and Regimes in Early Modern Europe, Cambridge, 1997.

http://dx.doi.org/10.1017/CBO9780511529016

Evans, R. J. W.: The Making of the Habsburg Monarchy 1550-1700, Oxford, 1979.

FELD, M.: «Middle class society and the rise of military professionalism: the Dutch army, 1589-1609», Armed Forces and Society, 1 (1975), pp. 421-442. http://dx.doi.org/10.1177/0095327X7500100404

Förster, S., Jansen, C. y Kronenbitter, G. (eds.): Rückkehr der Condottieri? Krieg und Militär zwischen staatlichem Monopol und Privatisierung: Von der Antike bis zur Gegenwart, Paderborn, 2010. 
Gommans, J.: Mughal Warfare, London, 2002. http://dx.doi.org/10.4324/9780203402580

Guthrie, W.: The later Thirty Years War. From the battle of Wittstock to the Peace of Westphalia, Westport/London, 2003.

GuY, A.: Oeconomy and Discipline. Officership and Administration in the British Army, 1714-63, Manchester, 1985.

Hahlweg, H. (ed.): Die Heeresreform der Oranier: das Kriegsbuch des Grafen Johann von Nassau-Siegen, Wiesbaden, 1973.

—: Die Heeresreform der Oranier und die Antike, Berlin, 1941.

Harding, R. y Solbes Ferry, S. (eds.): The Contractor State and Its Implications, 16591815, Las Palmas, 2012.

Heilmann, J.: Das Kriegswesen der Kaiserlichen und Schweden zur Zeit des Dreißigjäbrigen Krieges, Leipzig, 1850 - reprinted Krefeld, 1977.

- : Kriegsgeschichte von Bayern, Franken, Pfalz und Schwaben von 1506-1651, 2 vols; Munich, 1868.

Henschall, N.: The Myth of Absolutism. Change and Continuity in Early Modern European Monarchy, Harlow, 1992.

Hintze, O.: Gesammelte Abhandlungen zur allgemeinen Verfassungsgeschichte, 3 vols.; Göttingen, 1962-1967.

- : Historical Essays, Oxford, 1975.

PMCid:PMC236032

Hippler, T.: Citizen, Soldiers and National Armies. Military Service in France and Germany, 1789-1830, London, 2008.

KaISER, M.: «'Sed vincere sciebat Hanibal'. Pappenheim als empirischer Theoretiker des Krieges», en Neuhaus, H., Stollberg-Rilinger, B. (eds.): Menschen und Strukturen in der Geschichte Alteuropas, Berlin, 2002, pp. 201-227.

— : Politik und Kriegsführung Maximilian von Bayern, Tilly und die Katholische Liga im Dreißigjährigen Krieg, Münster, 1999.

KAPSER, C.: Die bayerische Kriegsorganisation in der zweiten Hälfte des Dreißigjährigen Krieges, Münster, 1997.

KIrk, T.: Genoa and the Sea. Policy and power in an early modern maritime Republic, 1559-1684, Baltimore and London, 2005.

KNight, R. y Wilcox, M.: Sustaining the Fleet, 1793-1815. War, the British Navy and the Contractor State, Woodbridge, 2010.

KolfF, D.: Naukar, Rajput and Sepoy. The ethnobistory of the military labour market in Hindustan, 1450-1850, Cambridge, 1990.

Konze, F.: Die Stärke, Zusammensetzung und Verteilung der Wallensteinischen Armee wäbrend des Jabres 1633. Ein Beitrag zur Heeresgeschichte des 30 Jährigen Krieges, Frankfurt-am-M, 1906.

Krebs, J.: Aus dem Leben des kaiserlichen Feldmarschalls Grafen Melchior von Hatzfeld, 1593-1636, 2 vols.; Breslau, 1910, 1926. 
LANE, F.: «Economic Consequences of Organized Violence», Journal of Economic History 18, 1958, pp. 401-417.

Lane, F.: «The Economic Meaning of War and Protection», en Lane, F.: Venice and History, Baltimore Md, 1966.

Mackay, R.: The Limits of Royal Authority. Resistance and Obedience in SeventeenthCentury Castile, Cambridge, 1999. http://dx.doi.org/10.1017/CBO9780511549397

Mallett, M.: Mercenaries and their Masters. Warfare in Renaissance Italy, London, 1974; $2^{\text {a }}$ edición, 2009.

MetTam, R.: Power and Faction in Louis XIV's France, Oxford, 1988.

Moran, D. y Waldron, A. (eds.): The People in Arms: Military myth and national mobilization since the French Revolution, Cambridge, 2003.

Parker, G.: «The Limits to Revolutions in Military Affairs: Maurice of Nassau, the battle of Nieuwpoort (1600) and the Legacy», Journal of Military History, 71, (2007), pp. 331-372. http://dx.doi.org/10.1353/jmh.2007.0142

- : The Army of Flanders and the Spanish Road, 1567-1659, 2a ed, Cambridge, 2004, pp. 190-91.

- The Military Revolution. Military Innovation and the Rise of the West, 1500-1800, $2^{\mathrm{a}}$ ed; Cambridge, 1996.

PARrot, D.: The Business of War. Military Enterprise and Military Revolution in Early Modern Europe, Cambridge, 2012.

Percy, S.: Mercenaries. The History of a Norm in International Relations, Oxford, 2007.

Porter, B.: War and the Rise of the State. The Military Foundations of Modern Politics, New York/Ontario, 1994.

Potter, M.: Corps and Clienteles. Public Finance and Political Change in France, Aldershot, 2003.

Redlich, F.: The German Military Enterpriser and his Work Force, 14th-18th Centuries. Vierteljahrschrift für Sozial- und Wirtschaftsgeschichte, 2 vols.; Wiesbaden, 1964.

Roberts, M.: «The Military Revolution, 1560-1660», Belfast, 1956. $2^{a}$ edición en RoberTs, Essays in Swedish History, London, 1967, pp. 195-225.

PMid:5303323 PMCid:PMC2554347

Root, H.: The Fountain of Privilege, Berkeley, CA, 1994.

Rousset, C.: Histoire de Lowvois et de son administration politique et militaire, 4 vols., Paris, 1879.

Rowlands, G.: The Dynastic State and the Army under Louis XIV. Royal Service and Private Interest, 1661-1701, Cambridge, 2002.

Rowlands, G.: The Financial Decline of a Great Power. War, Influence and Money in Louis XIV's France, Oxford, 2012.

SAlm, H.: Armeefinanzierung im Dreißigjäbrigen Krieg. Die Niederrheinisch-Westfälische Reichskreis, 1635-50, Münster, 1990. 
Schaufelberger, W.: Der Alte Schweizer und sein Krieg. Studien zur Kriegsfübrung vornebmlich im 15. Jabrhundert, Zurich, 1952.

PMid:12998623

Sörensson, P.: «Das Kriegswesen während der letzten Periode des Dreißigjährigen Krieges», en Rudolf, H. (ed.): DerDreißigjährige Krieg. Perspectiven und Strukturen, Darmstadt, 1977, pp. 431-57.

Stadler, B.: Pappenheim und die Zeit des Dreißigjäbrigen Krieges, Winterthur, 1991. PMCid:PMC1204579

Thompson, I. A. A.: War and Government in Habsburg Spain, 1560-1620, London, 1976.

Thomson, J.: Mercenaries, Pirates and Sovereigns. State Building and Extraterritorial Violence in early Modern Europe, New Haven/London, 1994.

Tilly, C.: «War Making and State making as Organized Crime», en Evans, P., RueschemeYer, D. y Skocpol, T. (eds.): Bringing the State Back In, Cambridge, 1985, pp. 169-191.

Tilly, C.: Coercion, Capital and European States AD 990-1990, Oxford, 1990.

Torres Sánchez, R. (ed.): War, State and Development. Fiscal-Military States in the Eighteenth Century, Pamplona, 2008.

- : "The Triumph of the Fiscal-Military State in the Eighteenth Century. War and Mercantilism», en Torres Sánchez, R.: War, State and Development. Fiscal-Military States in the Eighteenth Century, Pamplona, 2007, pp. 13-44.

Welti, L.: Graf Jakob Hannibal I. von Hohenems, 1530-1587. Ein Leben im Dienste des Katholischen Abendlandes, Innsbruck, 1954.

Wijn, J. W.: Het krijgswezen in den tijd van Prins Maurits, Utrecht, 1934.

Wilson, P.: Europe's Tragedy. A History of the Thirty Years War, London, 2009.

Wood, J.: The King's Army. Warfare, Soldiers and Society during the Wars of Religion in France, 1562-1576, Cambridge, 1996.

Zunckel, J.: Rüstungsgeschäfte im Dreißigjährigen Krieg: Unternehmerkräfte, Militärgüter und Marktstrategien im Handel zwischen Genua, Amsterdam und Hamburg, Berlin, 1997.

ZürCHER E.-J.: Fighting for a living. A comparative history of military labour, 1500-2000, Amsterdam, 2013.

Zwiedineck-SüdenHorst, H. Von: Kriegsbilder aus der Zeit der Landsknechte, Stuttgart, 1883. 